\title{
Storage Temperature and Duration Affect Quality and Post-storage Recovery of Vegetative Dendranthema $\times$ grandiflorum
}

\author{
Nihal C. Rajapakse', David Wm. Reed, and John W. Kelly ${ }^{1}$ \\ Department of Horticultural Sciences, Texas A\&M University, College Station, TX 77843
}

Additional index words. water loss, ornamental plants, postharvest, shipping, transpiration, chrysanthemum

\begin{abstract}
Experiments were conducted to evaluate Dendranthema $\times$ grandiflorum (Ramat.) Kitamura cv. Bright Golden Anne quality and post-storage growth following storage in the range of 5 to $35 \mathrm{C}$, initial soil water levels $(60 \%$, $80 \%, 100 \%)$, and durations ( 0 to 8 days). Transpiration rate showed a quadratic relationship with storage temperature. Initial soil water content had little effect on transpiration rate in dark storage environments. The lowest transpiration rate was observed in plants stored at 15 or $20 \mathrm{C}$. Amino acid (AA) leakage and post-storage growth were well-correlated. Plants stored at or above $25 \mathrm{C}$ became etiolated during storage, while storage at $15 \mathrm{C}$ or below did not cause etiolation. Temperatures at or below $15 \mathrm{C}$ did not affect subsequent growth rate of chrysanthemum plants. Storage at $20 \mathrm{C}$ and above caused a reduction in post-storage growth rate following 2 days of storage.
\end{abstract}

Due to the availability of inexpensive labor and low production costs, many large-scale floriculture and foliage plant producers have established production centers in developing countries in tropical and subtropical regions. The development of international markets for floricultural crops has increased the necessity for information on long-distance shipping and storage conditions before reaching the consumer.

Adverse storage environments, especially high temperature and low relative himidity, enhance water loss from plants due to an increase in the water potential gradient between the leaf and surrounding environment (Lorenzo-Minguez et al., 1985; Stanley et al., 1982, 1983). High transpiration rate during shipping/storage can induce water stress and enhance ethylene production and leaf abscission (Graves and Gladon, 1985). Peterson et al. (1980) reported that water stress is a major factor in leaf abscission of Ficus benjamina during storage. Prolonged exposure to adverse shipping/storage environments can deteriorate plant quality and reduce growth after storage or delay recovery from storage stress. Buck and Blessington (1982) reported that foliar damage was higher' when Ficus benjamina plants were exposed to high temperatures (37C). Tropical plants are susceptible to chilling damage when they are exposed to low temperatures ( $<7$ to 10C) (Buck and Blessington, 1982). Poole and Conover (1983) reported that Ficus benjamina dropped more leaves as storage duration increased, but shipping durations up to 21 days could be obtained without significant loss in quality if proper temperature was maintained. It is, therefore, essential to provide proper shipping/storage conditions to avoid any detrimental effects on plant quality.

The major objectives of this study were to evaluate the quality and post-storage growth of Dendranthema $\times$ grandiflower plants after storage at various temperatures and for several durations and to determine the best storage conditions without affecting plant quality.

\section{Materials and Methods}

Pretreatment and culture. Rooted $D . \times$ grandiflorum $\mathrm{cv}$. Bright Golden Anne shoot cuttings (Yoder Brothers, Barberton, Ohio)

Received for publication 11 Jan. 1990. Texas Agricultural Experimental Station publication no. TA 25966. The cost of publishing this paper was defrayed in part by the payment of page charges. Under postal regulations, this paper therefore must be hereby marked advertisement solely to indicate this fact.

${ }^{1}$ Present address: Dept. of Horticulture, Clemson Univ., Clemson, SC 29634. were planted (one plant per pot) in $10-\mathrm{cm}$ plastic pots $(\approx 0.5$ liter) containing 50 to $60 \mathrm{~g}$ (dry weight) 1 peat $: 1$ perlite $(\mathrm{v} / \mathrm{v})$ medium amended with (all per $\mathrm{m}^{3}$ ) $4.8 \mathrm{~kg}$ each of dolomite, gypsum, and superphosphate (0N-20P-0K); $1.1 \mathrm{~kg}$ MagAmp (W.R. Grace, Fogelsville, Pa.); $0.8 \mathrm{~kg} \mathrm{KNO}_{3}$ and $13.2 \mathrm{~g}$ fritted trace element. Plants were watered, as needed, with $\mathrm{N}, \mathrm{P}$, and $\mathrm{K}$ at 200, 87, and $165 \mathrm{mg} \cdot \mathrm{liter}^{-1}$, respectively, and allowed to establish in the greenhouse for 2 weeks under natural photoperiod. Environmental conditions during the growth period were: day/night temperatures, $27 \pm 3 \mathrm{C} / 20 \pm 2 \mathrm{C}$; day/night relative humidity, $38 \% \pm 15 \% / 70 \% \pm 10 \%$; light intensity of 300 to $1000 \mu \mathrm{mol} \cdot \mathrm{s}^{-1} \cdot \mathrm{m}^{-2}$.

Storage treatments and data collection. Two days before the storage experiment, plants were hand watered to runoff and excess water was allowed to drain overnight. The following morning, 100 plants were randomly selected and their weight at container capacity (CC) was recorded. Plant plus pot weight at $80 \%$ and $60 \%$ of $\mathrm{CC}$ and the amount of water needed to reattain $100 \%, 80 \%$, and $60 \%$ of CC after drying were calculated from the weight data. The plants were then allowed to dry until the desired percentage of CC was reached. The pots were covered with clear plastic film to prevent direct evaporation from the soil surface. Plants were then transferred to a storage chamber maintained at $5,10,15,20,25,30$, or 35C. Relative humidity in the chamber was maintained at $75 \% \pm 10 \%$ for each temperature, thus, the vapor pressure deficit ranged from $\approx 2.2$ to $\approx 15 \mathrm{mb}$. Air inside the storage chamber was circulated using a fan fixed onto the ceiling of the chamber. Plants were kept in darkness, except for use of a low-intensity, green safelight during the data collection. Plants were not watered during the 8 days of storage.

Weight measurements were taken twice daily at 0700 and $1900 \mathrm{HR}$ for 8 days. Transpiration rate was calculated from the weight-loss data.

AA leakage from leaf disks was estimated as described by Leopold et al. (1981). Two leaf disks, each $1.5 \mathrm{~cm}$ in diameter, were cut from the fourth leaf from the apex. Disk fresh weights were recorded and they were placed in glass vials containing $20 \mathrm{ml}$ deionized, distilled water. Glass vials were shaken in a water bath maintained at $22 \mathrm{C}$ for $2 \mathrm{hr}$. Absorbance readings of

Abbreviations: AA, amino acid; CC, container capacity; WPG, water potential gradient. 
the water were measured at $280 \mathrm{~nm}\left(\mathrm{~A}_{280}\right)$ with a spectrophotometer (Bausch and Lomb Spectronic 21, Rochester, N.Y.). Vials were then frozen overnight at $-70 \mathrm{C}$ in an ultra-low freezer to rupture cells, thawed, and shaken again for $2 \mathrm{hr}$ and $\mathrm{A}_{280}$ again was measured. Percentage AA leakage was calculated from $\mathrm{A}_{280}$ readings of original and frozen samples.

At the end of the experiment, plants were harvested and leaf area was measured with a LI-COR-3050 area meter (LI-COR, Lincoln, Neb.).

Representative plants placed in each storage temperature were taken out after $0,2,4,6$, or 8 days of storage and placed back in the greenhouse. Plant height increase was recorded in the greenhouse for 3 weeks at 4-day intervals.

Experimental design and analysis. Plants were arranged in a split-plot. design with 10 replications for weight loss measurements and five replications for other characteristics measured. Temperature and initial soil water level were the whole-plot and split-plot factors, respectively. Plants in the post-storage growth experiment were arranged in a split-split plot design. Temperature, initial water level, and storage duration were whole-, split-, and split-split plot factors, respectively. The data were analyzed using analysis of variance procedure. Regression analysis was carried out to test for the temperature and storage duration effects. Least square means were computed and differences in the means were tested using least significant difference procedure, where necessary.

\section{Results and Discussion}

The transpiration rate rapidly declined after placing plants in dark storage and leveled off after $\approx 48 \mathrm{hr}$ (Fig. 1). Plants stored at 30 and $35 \mathrm{C}$ showed an initial decline of transpiration rate followed by a rapid increase after 60 and $108 \mathrm{hr}$, respectively. Plants stored at these two temperatures showed severe damage at the end of storage.

Slight diurnal fluctuation of transpiration rate was observed in. plants stored at 5 and $10 \mathrm{C}$, probably due to incomplete sto-

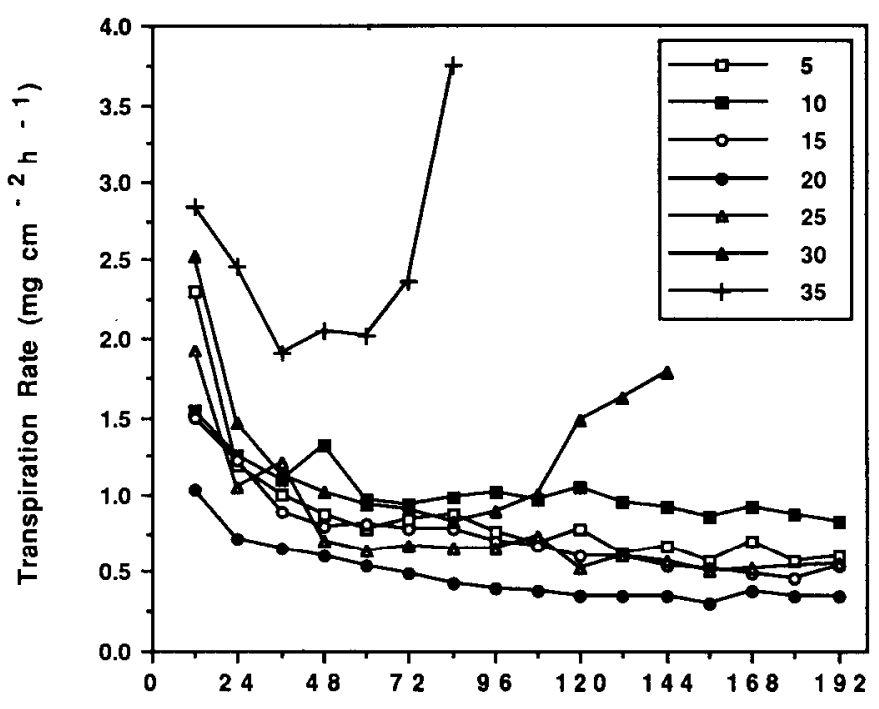

Fig. 1. Effect of storage temperature on average transpiration rate of Dendranthema $\times$ grandiflorum during storage. Each point indicates the average transpiration rate of 10 plants for the corresponding time period. Vapor pressure deficit ranged from $\approx 2.2$ to $\approx 15 \mathrm{mb}$ in the temperature range. matal closure in the dark at these temperatures. It has been reported that stomata of some species do not close completely in darkness (Kramer, 1983; Rajapakse et al., 1989). Wilson (1983) reported that a low temperature "locks open" the stomata of some plants. Slow stomatal response has also been reported at low temperatures (McWilliam et al., 1982).

At all temperatures, plants with higher soil water levels showed higher average transpiration rates than those held at a lower CC (Fig. 2). The difference in transpiration rates between soil water levels was highest between 15 and 20C, with a smaller difference at extreme temperatures. In previous studies, a decrease in transpiration rate has been reported with decreasing soil water content under greenhouse conditions (Ceulemans et al., 1979; Morison and Gifford, 1984). In light, stomata are fully open and both stomatal and cuticular transpiration account for the water loss. As water stress progresses, stomata begin to close, reducing the transpiration rate. In the present study, conducted in darkness, the stomata were probably closed or partially open; thus, the effect of soil water content on transpiration was not as drastic as under normal greenhouse conditions. Cuticular transpiration may have accounted for the majority of water loss in the present experiment due to closed or partially open stomata and poor epicuticular wax development in chrysanthemum leaves (Rajapakse et al., 1988).

The lowest transpiration rate was observed in plants stored at 15 and 20C. The slightly higher transpiration rates at 5 and 10C could be due to partial opening of the stomata or impaired stomatal movement as was shown at low temperatures for some tropical plants (Wilson, 1983). The relationship between transpiration and storage temperature is explained by a quadratic model.

The increase in transpiration rate with increasing temperature can be partially explained by the increase in water potential gradient (wpg) between the leaf surface and ambient air. Lorenzo-Minguez et al. (1985) reported that transpiration of Schef-

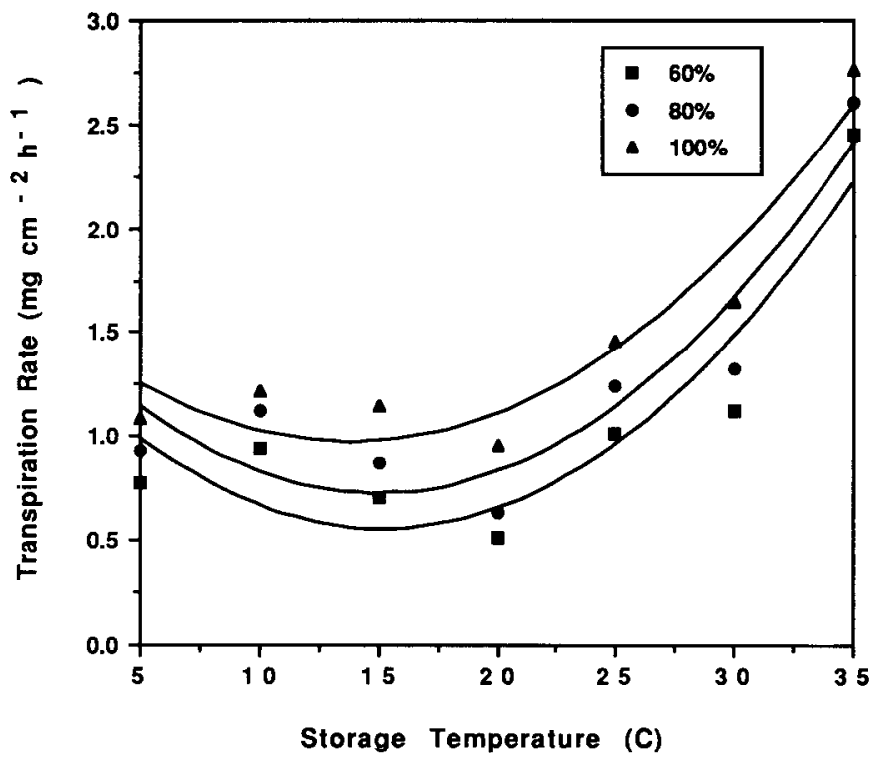

Fig. 2. Effect of storage temperature on transpiration rate of Dendranthema $\times$ grandiflorum during storage at different initial soil water levels, expressed as CC. Each point indicates the average transpiration during storage period of 10 plants. Best fit regression equations are: $100 \% \mathrm{CC}, \mathrm{Tr}=1.67-0.100 \mathrm{~T}+0.004 \mathrm{~T}^{2}, R^{2}=0.90 ; 80 \%$ $\mathrm{CC}, \mathrm{Tr}=1.67-0.127 \mathrm{~T}+0.004 \mathrm{~T}^{2}, \mathrm{R}^{2}=0.89 ; 60 \% \mathrm{CC}$, $\operatorname{Tr}=1.67-0.129 \mathrm{~T}+0.004 \mathrm{~T}^{2}, \mathrm{R}^{2}=0.89$. 
flera increased with increasing wpg. An increase in air temperature without increasing absolute humidity of the air increases the rate of transpiration because of the increase in wpg between leaf surface and surrounding environment (Kramer, 1983).

AA leakage was not different between soil water levels and, hence, the AA leakage data from three soil water levels were pooled for further analysis. In contrast, Leopold et al. (1981) reported that desiccation of cowpea leaf tissues increased the AA leakage in proportion to the level of desiccation. Bewley et al. (1978) also demonstrated that AA leakage increased with the development of water stress.

AA leakage increased as the storage temperature and duration increased (Fig. 3). Plants stored at 30 or 35C showed the highest AA leakage and the rate of AA leakage rapidly increased as storage duration increased. At another temperatures, AA leakage increased at a slower rate over the storage time. Plants stored at $15 \mathrm{C}$ showed a higher rate of AA leakage than those at $25,20,10$, or $5 \mathrm{C}$.

The leakage of solutes and AA from tissues has been used as a measure of membrane damage (Ingram, 1985; McWilliam, 1980). The increase in AA leakage at high storage temperatures and longer durations indicated that membrane damage occurred at these conditions.

Membrane damage during storage may be a major factor in determining quality and recovery of plants in post-storage. The extent of membrane damage depends on duration of exposure, plant species, and temperature. A sigmoidal response of solute leakage to temperature and exposure time has been reported with Pittosporum tobira root cells (Ingram, 1985). At extremely high temperatures, short exposure can enhance the leakage of solute, indicating severe membrane damage. Once the membranes are severely damaged, the plant may not be able to recover from the storage stress. Storage of plants at optimum temperatures minimizes membrane damage and allows better recovery after storage. Chilling temperatures also have been reported to increase electrolyte leakage from chilling-sensitive species (Wang, 1982). Low storage temperatures, in this study, did not damage the membranes, indicating the tolerance of chrysanthemum to low temperatures.

Soil water content did not affect extension growth during

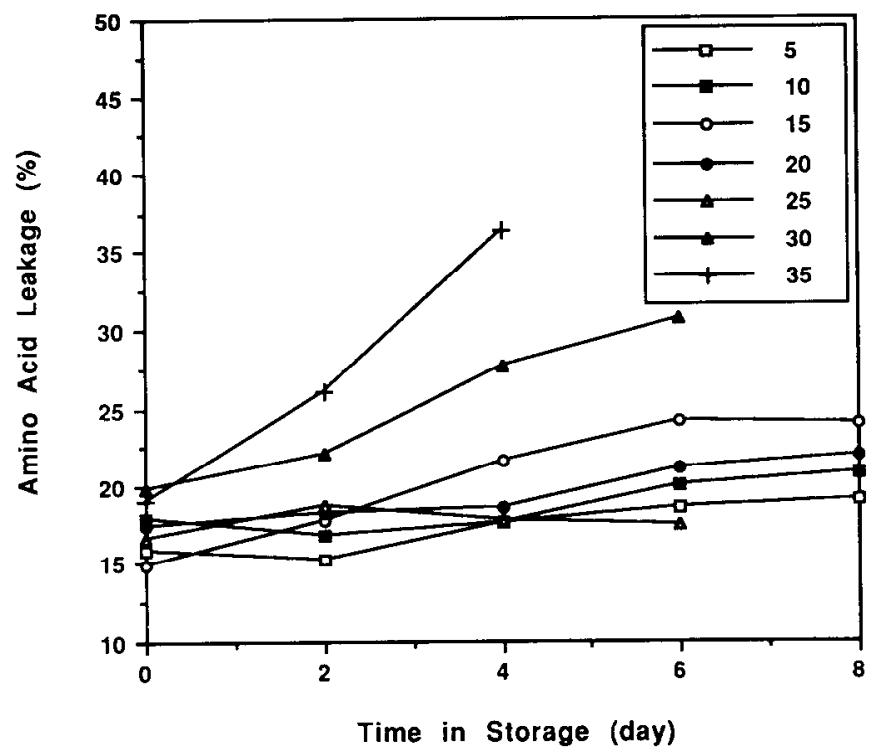

Fig. 3. Effect of storage temperature and duration on percentage AA leakage of Dendranthema $\times$ grandiflorum. storage, and, therefore, data were pooled to calculate rate of stem elongation. Stem elongation in storage increased as the storage temperature increased up to 25C (Fig. 4). The lowest rate of stem elongation was found at $5 \mathrm{C}$ while it was highest at $25 \mathrm{C}$. The rate of stem elongation declined as the time in storage at $15 \mathrm{C}$ or above increased, with $\approx 30 \%$ decrease in the plants stored at these temperatures (data not shown). Stem elongation in storage is undesirable because it is due to etiolation and not to dry matter accumulation. Storage at 5 to $15 \mathrm{C}$ would be best for chrysanthemum for short durations because the plants did not elongate in this temperature range.

Measurements of post-storage growth of chrysanthemum plants in the greenhouse indicated that storage at 5,10 , or $15 \mathrm{C}$ did not affect subsequent growth rate after any storage duration (Fig. 5). However, plants stored at $20 \mathrm{C}$ or above showed a reduction. in post-storage growth in the greenhouse. The most rapid reduction occurred with 2 days of storage; thereafter, the growth rate remained steady with increasing storage time. Plants stored at $30 \mathrm{C}$ for $>4$ days or the plants stored for $>2$ days at $35 \mathrm{C}$ did not recover after placing in the greenhouse due to severe foliar damage.

AA leakage and recovery from storage stress were closely related. Plants stored at 30 or $35 \mathrm{C}$ had a high AA leakaze and did not recover in the greenhouse. Plants that had low AA leakage recovered well in the greenhouse. This result indicates the need for minimum storage in order to obtain the best quality plants after storage at ambient temperatures or above and the importance of low-temperature storage if long-term shipping/ storage is necessary. Buck and Blessington (1982) observed that Ficus benjamina and Ficus lyrata stored at 4 or $37 \mathrm{C}$ had less recovery after storage as the duration of exposure increased.

Our results indicate that the transpiration rate in storage is mainly determined by temperature; soil water content had little influence. Temperatures $>20 \mathrm{C}$ caused plant etiolation and loss of quality after removal from storage. Plant injury was severe and recovery from storage stress was slow as storage duration and temperature increased. Plants stored between 5 and $15 \mathrm{C}$ gave the best quality and post-storage recovery. Selection of a low temperature is important if long-term shipping/storage is necessary before chrysanthemums reach the consumer. How-

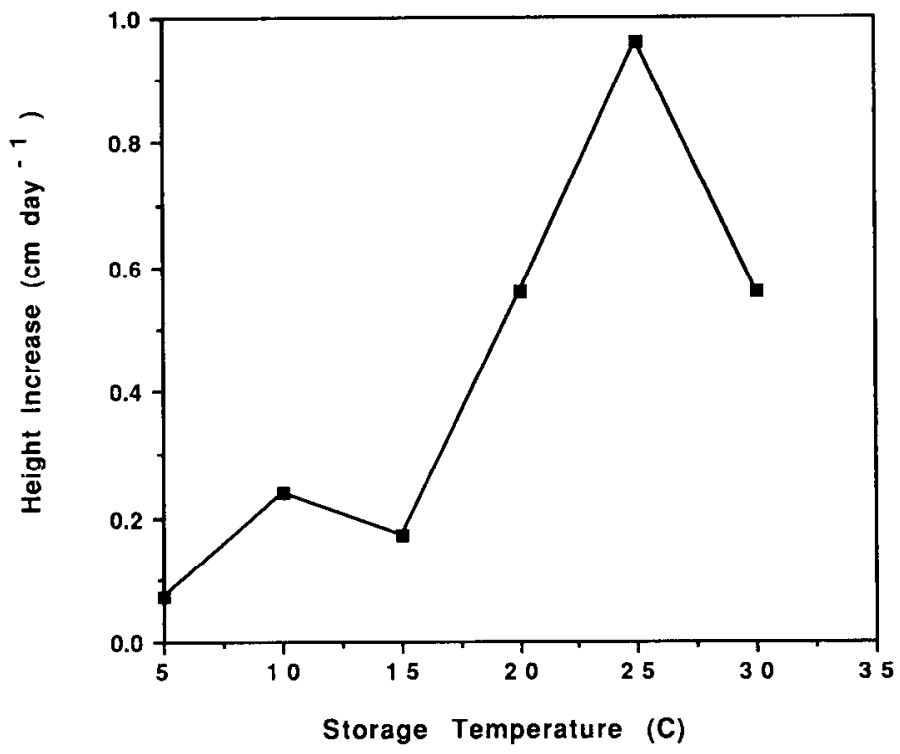

Fig. 4. Effect of storage temperature on height increase of Dendranthema $\times$ grandiflorum during storage. 


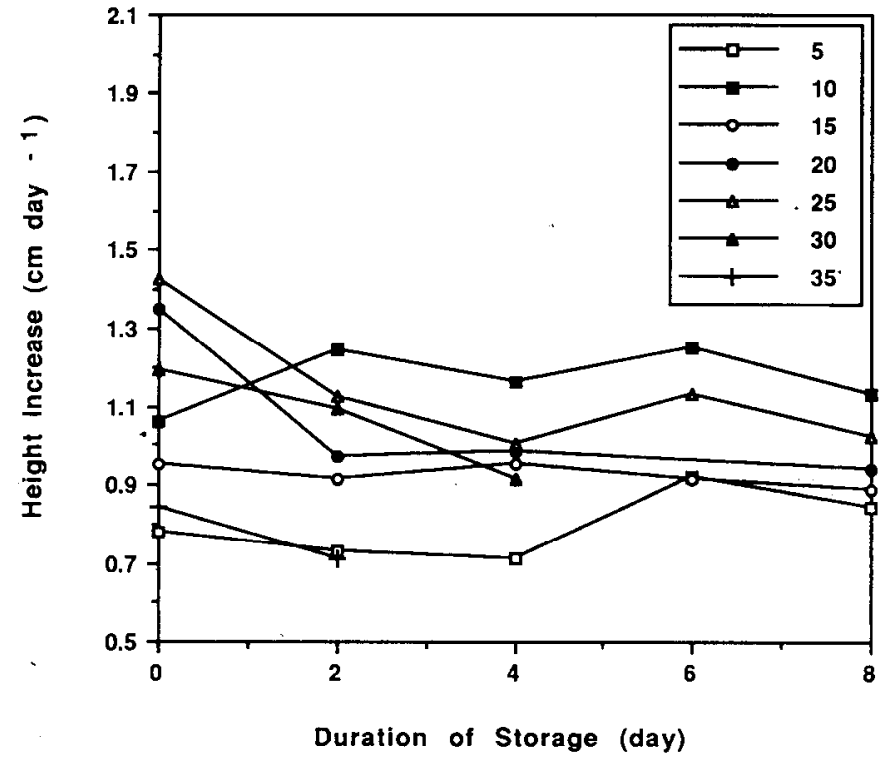

Fig. 5. Effect of storage temperature and duration on average poststorage growth of Dendranthema $\times$ grandiflorum in greenhouse. Each point indicates the average growth of five replicates and three soil water levels. Plant height increase was measured in the greenhouse for 3 weeks at 4-day intervals.

ever, it is important to minimize duration of dark shipping/ storage to obtain best quality after storage.

\section{Literature Cited}

Bewley, J. D., P. Halmer, J. E. Krocho, and W. E. Winner. 1978. Metabolism of a drought tolerant and a drought sensitive moss, p. 185203. In: J.H. Crowe and J.S. Clegg (eds.). Dry biological systems. Academic, New York.

Buck, T.L. and T.M. Blessington. 1982. Postharvest effects of temperature during simulated transit on quality factors of two Ficus species. HortScience 17:817-819.

Ceulemans, R., I. Impens, and R. Gabriels. 1979. Comparative study of leaf water potential, diffusive resistance and transpiration of azalea cultivars subjected to water stress. HortScience 14:507-509.

Grave, W.R. and R.J. Gladon. 1985. Water stress, endogenous ethylene and Ficus benjamina leaf abscission. HortScience 20:273-275.
Ingram, D.L. 1985. Modeling high temperature stress and exposure time interactions on Pittosporum tobira root cell membrane thermostability. J. Amer. Soc. Hort. Sci. 110:470-473.

Kramer, P.J. 1983. Water relations of plants. Academic, New York.

Leopold, A. C., M.E. Musgrave, and K.M. Williams. 1981. Solute leakage resulting from desiccation. Plant Physiol. 68:1222-1225.

Lorenzo-Minguez, P., R. Ceulemans, R. Gabriels, I. Impens, and O. Verdonck. 1985. Response of gas exchange behavior of Schefflera arboricola to air humidity and temperature. HortScience 20:10601062.

McWilliam, J.R. 1980. Adaptation of plants to water and high temperature stress: summary and synthesis adaptation to high temperature stress, p. 444-447. In: N.C. Turner and P.J. Kramer (eds.). Adaptation of plants to water and high temperature stress. Wiley, New York.

McWilliam, J. R., P.J. Kramer, and R.L. Musser. 1982. Temperature induced water stress in chilling sensitive plants. Austral. J. Plant Physiol. 9;343-352.

Morison, J.I.L. and R.M. Gifford. 1984. Plant growth and water use with limited water supply in high $\mathrm{CO}_{2}$ concentrations. I. Leaf area, water use and transpiration. Austral. J. Plant Physiol. 11:361-374.

Peterson, J. C., J.N. Sacalis, and D.J. Durkin. 1980; Promotion of leaf abscission in intact Ficus benjamina by exposure to water stress. J. Amer. Soc. Hort. Sci. 105:788-793.

Poole, R.T. and C.A. Conover. 1983. Influence of simulated shipping environments on foliage plant quality. HortScience 18:191-193.

Rajapakse, N. C., J.W. Kelly, and D. Wm. Reed. 1988. Transpiration and water use of potted floricultural plants under low light conditions. J. Amer. Soc. Hort. Sci. 113:910-914.

Rajapakse, N. C., D. Wm. Reed, and J.W. Kelly. 1989. Effect of pretreatment on transpiration of Chrysanthemum morifolium in the dark. HortScience 24:998-1000.

Stanley, C. D., B.K. Harbaugh, and J.F. Price. 1982. The use of leaf water potential for estimating the effects of seasonal water stress on yield of Chrysanthemum. HortScience 17:812-813.

Stanley, C. D., B.K. Harbaugh, and J.F. Price. 1983. Environmental factors influencing leaf water potential of Chrysanthemum. J. Amer. Soc. Hort. Sci. 108:237-240.

Wang, C.Y. 1982. Physiological and biochemical response of plants to chilling stress. HortScience 17:173-186.

Wilson, J.M. 1983. Interaction of chilling and water stress, p. 133147. In C.D. Raper, Jr. and P.J. Kramer (eds.). Crop reactions to water and temperature stress in humid, temperature climates. Grandview Press, Boulder, Colo. 